\title{
Correction to: Neurovascular structure-adjacent frozen-section examination robotic-assisted radical prostatectomy: outcomes from 500 consecutive cases in the UK
}

\author{
Jonathan Noël ${ }^{1}$ - Neil H. Spencer ${ }^{2}$. Siya Lodia ${ }^{1}$. Seiver Karim ${ }^{1}$ - Surina Taneja ${ }^{1}$ - Darius Moghanchizadeh ${ }^{1}$. \\ Arvind Nayak ${ }^{1}$ - Ashwin Tamhankar ${ }^{1}$ - Seema Angra ${ }^{3} \cdot$ Rajiv Swamy $^{3} \cdot$ Samita Agarwal $^{3}$. Ashish Narula ${ }^{3}$. Tim Lane ${ }^{1}$. \\ Jim Adshead ${ }^{1} \cdot$ Nikhil Vasdev $^{1,4}$
}

Published online: 27 November 2021

(c) Springer-Verlag London Ltd., part of Springer Nature 2021

\section{Correction to: Journal of Robotic Surgery https://doi.org/10.1007/s11701-021-01324-2}

The original version of this article unfortunately contained a mistake. XML has the incorrect equal contribution information. On PubMed the citations states that Jonathan Noël and Neil H Spencer contributed equally by a superscript \#.

The correct article note should be.

Jim Adshead and Nikhil Vasdev are joint senior authors. The original article has been corrected.

Jim Adshead and Nikhil Vasdev are joint senior authors.

The original article can be found online at https://doi.org/10.1007/ s11701-021-01324-2.

Jonathan Noël

Dr.Jnoel@gmail.com

1 Hertfordshire and Bedfordshire Urological Cancer Centre, Department of Urology, Lister Hospital, East and North Hertfordshire NHS Trust, Stevenage, UK

2 University of Hertfordshire, Statistical Services and Consultancy Unit, Hatfield, UK

3 Lister Hospital, East and North Hertfordshire NHS Trust, Stevenage, UK

4 School of Life and Medical Sciences, University of Hertfordshire, Hatfield, UK
Publisher's Note Springer Nature remains neutral with regard to jurisdictional claims in published maps and institutional affiliations. 